\title{
Importância do Ludodiagnóstico e do Brincar na Psicanálise Infantil
}

\author{
Importance of Ludodiagnostic and Play in Child Psychoanalysis
}

Daiane da Silva Assis ${ }^{+*}$, Michele Mariana Vieira Ferreira Santos*

Como citar esse artigo. Assis, DS; Santos, MMVF. Importância do Ludodiagnóstico e do Brincar na Psicanálise Infantil. Revista Mosaico. 2019 Jul/Dez:; 10 (2): SUPLEMENTO $16-25$.

\section{Resumo}

Brincar é uma atividade natural da criança, que também é usada como técnica de análise infantil. Considerando que a criança tem limitações em sua linguagem verbal, brincar pode ser o meio de acesso para conhecer seus sentimentos e pensamentos. Esses princípios levaram à formação do Ludodiagnóstico, um método projetivo para o conhecimento do paciente através de jogos e brincadeiras. Assim, a revisão da literatura dos autores referenciados no tema contribuiu para reforçar a importância dessa linguagem, bem como os fatores inerentes. Também é possível observar que o Ludodiagnóstico é uma técnica bem estabelecida e que, apesar das pequenas divergências de opinião entre os autores, pode ser a melhor maneira de entender e estabelecer vínculos, trazendo benefícios para a criança. No entanto, é necessário que o profissional domine conhecimentos específicos dos procedimentos que devem ser realizados.

Palavras-Chave: Ludodiagnóstico, Brincar, Psicanálise infantil.

\begin{abstract}
Playing is a natural activity of the child, which is also used as a technique for child analysis. Considering that the child has limitations in his verbal language, playing can be the way of access to know his feelings and thoughts. These principles led to the formation ofLudodiagnostic, a projective method for knowledge of the patient through games and plays. The literature review of the authors referenced about this contributed to reinforce the importance of this language, as well as the intrinsic factors. It is also possible to observe that Ludodiagnostic is a well-established technique and that, despite small differences of opinion between authors, may be the best way to understand and establish bonds, bringing benefits to the child. However, it is necessary for the professional to master specific knowledge of the procedures that must be realized. Keywords: Ludodiagnostic, Play, Child Psychoanalysis.
\end{abstract}

\section{Introdução}

O brincar na psicanálise com crianças, de acordo com Felice (2003), possibilita ao profissional da área de psicologia se deparar com uma questão fundamental nessa modalidade de trabalho, referente ao lugar da brincadeira nas sessões analíticas. Ainda de acordo com o autor, houve alterações significativas na maneira de se compreender esta questão (análise) pelos estudiosos da psicanálise.

Através da observação das brincadeiras infantis é possível obter uma visão geral da vivência da criança, externalizando seus conflitos internos e externos. Enfatizar esse tema nos remete aalgumas dúvidas e questionamentos. Quando nos referimos ao ludodiagnóstico, faz-se, na maioria das vezes, uma associação com o uso dos testes e o diagnóstico em si, mas o brincar nesse processo nos permite ter uma visão mais ampla do desenvolvimento da criança em análise.

Diante destas observações, relata o autor Felice (2003), pode-se, então, avaliar nas crianças, através do brincar, seus possíveis conflitos internos e externos que não encontram expressão na fala, mas que brincando, permitiriam sua externalização e possível elaboração. Torna-se de grande relevância o aprofundamento no tema, visto que, como revelado através de pesquisas bibliográficas, o estudo nos leva à reflexão sobre a técnica mais adequada para adentrarmos nesse mundo, a fim de compreendê-lo e facilitar os processos de elaborações psíquicas.

De acordo com o estudo serão respondidas as seguintes questões de problematização no decorrer do artigo: O que é o ludodiagnóstico, qual a importância

Afiliação dos autores: † raduanda em Psicologia - Curso de Psicologia - Psicologia da Universidade de Vassouras - Vassouras - RJ - Brasil.

\$ Mestre em Psicologia - Curso de Psicologia - Universidade de Vassouras - Vassouras - RJ - Brasil. 
do brincar à luz do senso comum e dentro do processo do ludodiagnótico infantil, quais os teóricos e suas considerações a respeito do brincar em análise, e se é possível chegar a um diagnóstico com a observação do brincar.

Este trabalho baseia-se em revisão de literatura relacionada com estudos no âmbito do atendimento psicanalítico e psicodiagnóstico de crianças. Por exemplo, o estudo de Affonso (2012) traz a possibilidade de uma investigação clínica, utilizando brincadeiras planejadas ou não para estabelecer um vínculo terapêutico, proporcionando o desenvolvimento e o diagnóstico de sua personalidade.

Além disso, o presente artigo discute o brincar, linguagem típica da criança, um dos principais métodos de avaliação da psicodinâmica infantil já que, em muitos casos, a fala pouco comparece verbalmente, mas pode ser viabilizada através de desenhos, jogos, brincadeiras e outras representações. Para isso, lançaremos mão de teóricos clássicos e pesquisadores referenciados na área,como Donald Winnicott, Melanie Klein, Arminda Aberastury e Ana Freud bem como artigos contemporâneos de demaisestudiosos.

\section{Breve contexto da Psicanálise Infantil}

Construída há mais de cem anos, a Psicanálise é um campo de atuação que teve suas primeiras ideias delineadas por Sigmund Freud, e passou por um intenso desenvolvimento com o surgimento de teorias que complementam os pressupostos iniciais (SEI; CINTRA, 2013).

Incialmente, os métodos da teoria psicanalítica eram focados em adultos e posteriormente foram desenvolvidos no campo da análise da criança. Entretanto, a partir de atendimentos a essa faixa etária, Freud observou que as causas de transtornos se localizavam na infância (PAULA, 2017).

De acordo Arenales-Loli (2014), Freud foi o primeiro a observar este mecanismo psicológico do brincar ao observar o seu neto de 18 meses brincando de esconder e encontrar um carretel repetidas vezes. Ao visualizar as expressões de alegria neste encontro, Freud pensou sobre a possibilidade de este carretel representar a mãe e esta brincadeira ser uma possibilidade de elaboração diante da ansiedade de separação desta. Assim, o que era vivenciado de forma passiva, através desta experiência lúdica, poderia ser neste momento vivenciado de forma ativa pelo garoto, possibilitando uma organização de suas angústias.

Mais tarde, foi observado por Arminda Aberastury que esse modelo descrito por Freud, surge muito mais cedo, entre os 4 e 6 meses, e se relaciona à etapa que o bebê tenta elaborar a necessidade de se desprender da relação única com a mãe para poder passar à relação com o pai, estabelecendo, deste modo, a tríade paimãe-filho, que formará a base das futuras relações e o caminho para interesses múltiplos no mundo exterior, formando laços com pessoas e objetos cada vez mais variados e numerosos (ARENALES-LOLI, 2014).

Entretanto, considera-se que a análise com crianças se iniciou com a publicação do caso de Herbert Graf, denominado "Pequeno Hans - Análise de uma Fobia em um Menino de Cinco Anos", por Freud, em 1909. Nesse caso, Max Graf, pai do menino, descrevia suas brincadeiras e comportamento, sob a supervisão de Freud, que encontrou o menino apenas uma vez (COSTA, 2010).

De acordo com Paula (2017), não era a intenção de Freud elaborar uma técnica de atendimento infantil, mas confirmar que a causa das neuroses estava presente na infância e fundamentar sua tese acerca da sexualidade infantil, exposta em 1905 nos Três Ensaios Sobre a Teoria da Sexualidade.

O pai de Hans, conhecedor dos estudos de Freud, se dispôs a observar a vida do menino e a enviar o material obtido, com o intuito de confirmar as teorias freudianas sobrea sexualidade infantil. Ao longo da experiência, pode-se perceber que Hans eracheiode questionamentos sobre os órgãos sexuais, as diferenças anatômicas entre o homem e a mulher, onascimento de bebês e envolvido por uma série de fantasias ligadas a masturbação, ao Édipo e aosentimento de castração (SILVA, 2016).

Segundo Costa (2010), a princípio, ele nem mesmo acreditava que fosse possível analisar uma criança, mas a experiência com pequeno Hans fez com que ele mudasse de ideia. Esse caso singular foi um marco no desenvolvimento da psicanálise, pois pôde demonstrar que a realidade psíquica da criança se assemelha à do adulto em suas angústias, fantasias e desejos.

Considerando que a expressão verbal de uma criança é diferente do adulto, Freud enfrentou problemas para analisar o caso, pois havia dificuldades para a associação livre. Desta forma, teve que buscar outros meios para acessar o inconsciente, de forma que muitas das interpretações referem-se a brincadeiras, sonhos e fantasias (PAULA, 2017).

O caso passou então a indicar para Freud possibilidades e potencialidades do tratamento psicanalítico infantil. Além disso, ficou evidente que os eventos traumáticos na infância podiam gerar problemas emocionais futuros. A essência do brinquedo foi descrita como forma de colocar em movimento situações de angústia e vivências traumáticas, visto que a criança não brinca apenas com aquilo que é prazeroso, mas também como uma estratégia para repetição de situações consideradas dolorosas. Mais tarde, Freud reconheceu que o tratamento feito em adultos deve ser feito de maneira distinta em crianças. É necessária uma série de adaptações na técnica, em função da constituição do 
mundo interno de cada um deles (SEI;CINTRA, 2013).

De acordo com Arenales-loli et al. (2013), a conduta técnica adotada por Freud a partir desse caso foi a recomendação de que o próprio pai conduzisse a análise de seu filho, algo que atualmente soaria no mínimo estranho e inadequado. Entretanto, para o psicanalista, na época, foi considerado essencial para um trabalho analítico com crianças, pois somava numa só pessoa o "carinho afetuoso com o interesse científico".

Efetivamente, o interesse pela psicanálise infantil surgiu com estudos pós-freudianos, através de Hemine Von Hug-Hellmuth, Anna Freud e Melanie Klein. Partindo do caminho aberto por Freud, elas publicaram seus primeiros trabalhos sobre o tema, resultando em teorias diversas e até mesmo opostas em relação à posição da criança como sujeito inconsciente (LOPES, 2012; GAGLIOTTO et al., 2014).

De acordo com Paula (2017), Hermine Von Hug-Hellmuth foi uma das primeiras a tentar superar as dificuldades nos atendimentos com criança. Além de observar o jogo, também brincava com seus pacientes. Costa (2010) relata que ela visitava as crianças em seus lares com o objetivo de observá-las em suas atividades. Utilizava jogos e desenhos, afirmando que, com material, as crianças elaboravam as situações difíceis e traumáticas. Em seu método, a interpretação do material inconsciente combinava-se com a influência pedagógica direta.

Dessa forma, a principal contribuição de HugHellmuth se tratava da técnica de análise de crianças, apresentando meios para adquirir a confiança das crianças e a importância de evitar sugestões nos atendimentos. Utilizava o brincar como instrumento clínico, contribuindo para a remoção de sintomas. Sua maior preocupação nos atendimentos era que não houvesse ações invasivas do terapeuta durante as interpretações feitas (SEI; CINTRA, 2013).

Suas observações foram publicadas em 1921 e foram consideradas muito valiosas principalmente porque confirmavam os conceitos de Freud sobre a primeira infância. Porém, desaprovava a ideia de analisar crianças muito pequenas, pois acreditava que nesses casos a análise, em razão de seu poder de mobilizar o recalque e ao fortalecer as tendências impulsivas da criança, poderia prejudicá-la. Também afirmava que o analista deveria contentar-se em obter êxitos apenas parciais e de contar também com recaídas (COSTA, 2010).

Posteriormente, entrou em cena Anna Freud, que retomou muitas das teorias de sua antecessora, como a impossibilidade de atender crianças muito pequenas e o caráter educativo e pedagógico dos atendimentos (SEI; CINTRA, 2013).

Considerava as crianças muito frágeis para submeterem-se a uma análise e não acreditava que elas pudessem desenvolver a transferência, tampouco associar livremente, devido a sua imaturidade psíquica. Com base nesse raciocínio, ela defendia que a abordagem psicanalítica deveria vir associada a uma ação educativa, de modo que o analista de crianças, além do treinamento analítico propriamente dito, também deveria possuir o conhecimento pedagógico (LOPES, 2012).

Em sua obra, descreveu o atendimento de dez crianças, na faixa etária entre seis e doze anos, com neurose grave, e concluiu que a situação analítica do adulto e da criança é diferente, já que a criança não tem consciência de sua enfermidade, nem desejo de cura, não se analisa por livre decisão delas e o mais importante: não são capazes de fazer associações verbais. Anna Freud utilizava a interpretação de sonhos e desenhos, restringindo a utilização de jogos, aprimorando uma orientação essencialmente pedagógica, voltada para o ego consciente mais do que para as profundezas do inconsciente, desta forma, reeducava a criança para uma adaptação à realidade, visando um convívio melhor em família (PAULA, 2017).

Já Melanie Klein optava pelo uso do brinquedo como forma de acesso ao inconsciente da criança. Interpretou de maneira mais profunda o material trazido pela criança, dando maior valor para o jogo. Como princípio básico, na sua técnica, o jogo representava o alívio da angústia e, deste modo, a possibilidade de analisar o ego da criança e a sua relação com a realidade. Acreditava que o psicanalista não deveria tomar o papel de educador, pois as ansiedades da criança são muito grandes e a pressão a estas faz com que tomem compulsão à repetição (SEI; CINTRA, 2013; KLIPAN; MELLO NETO, 2012).

Klein realizava observação de bebês e atendimentos de crianças, em queintroduziu de forma consciente e sistemática o uso de brinquedos, desenhos e jogos na técnica. Afirmava que, ao brincar, a criança vence realidades dolorosas e domina medos instintivos, projetando-os no exterior por meio dos brinquedos. Assim, a criança expressa suas fantasias, seus desejos, e suas experiências reais de um modo simbólico, através de brincadeiras e jogos, e na medida em que as figuras aparecem no jogo da criança através do mecanismo de simbolização e personificação, podemos compreender a formação de seu superego e amortecer sua severidade (PAULA, 2017).

Como um exemplo, Melanie Klein (1955) citada por Arenales-loli (2014, p. 43) relata: "Descobri que a atitude da criança com um brinquedo que ela danificou é muito reveladora". A autora observou a agressividade sendo expressa pelo brincar da criança e ainda relata que, em caso de quebra desse brinquedo, são realizados ataques mais agressivos, representando a culpa que pode se seguir logo após a criança ter quebrado algo. Essa culpa refere-se não apenas ao estrago real, mas ao que o brinquedo representa para a criança, como por exemplo, um irmãozinho ou um dos pais. 
Posteriormente Anna Freud reconheceu as descobertas de Melanie Klein, em que estabeleceu a correspondência entre a associação livre e as técnicas de jogo (LOPES, 2012).

As fundamentações de Anna Freud e Melanie Klein predominaram por alguns anos. Entretanto, com o passar do tempo nota-se uma grande influência das ideias de Donald Winnicott, pediatra e psicanalista que, a partir da observação das crianças e de seu crescimento, acabou por enfatizar o jogo como elemento essencial no trabalho analítico. Na visão deste autor, além de interpretar, é também de grande importância a sustentação ofertada na relação terapêutica (SEI; CINTRA, 2013).

De acordo com Freitas (2016) e Carneiro e Silva (2013), a partir do acompanhamento do desenvolvimento físico e emocional de inúmeras crianças, Winnicott, através de suas observações, identificou o brincar como um elemento universal da natureza humana, mesmo que nem todos estivessem passíveis a essa oportunidade e/ ou possibilidade. Considerava o brincar em si mesmo, psicoterapêutico e que talvez, somente no brincar, é que a criança e o adulto podem desfrutar de sua liberdade de criação.

Para chegar a essa compreensão Winnicott (1975) desenvolveu seus princípios a partir daquilo que advém dos fenômenos transicionais, entendidos como o momento que a criança inicia sua separação da mãe. Esse momento, que vem ocorrendo desde o desmame, causa a substituição da mãe por outra coisa. É necessário que ocorra uma adaptação no ambiente de acordo com as necessidades do bebê de tal modo que ele possa adquirir confiança em si mesmo e no mundo.

De acordo com Safra (2012), Arminda Aberastury realizou importantes contribuições, ao desenvolver o ludodiagnóstico como uma modalidade de realização de diagnóstico psicanalítico em que o processo transferencial e o jogo possibilitariam a compreensão da angústia do paciente.

Em suas pesquisas, Aberastury entendeu que a criança não só estabelece uma transferência positiva e/ ou negativa com o psicoterapeuta, como também é capaz de estruturar, através dos brinquedos, a representação de seus conflitos básicos, suas principais defesas e fantasias de doença e cura, deixando em evidência, já nos primeiros encontros do acompanhamento, o seu funcionamento mental. Aberastury sugeriu, ainda, que possivelmente esses fenômenos surgem devido ao temor da criança de que seu psicoterapeuta repita com ela a conduta negativa dos objetos originários que lhe provocaram a perturbação, prevalecendo agora o desejo de que o psicólogo assuma uma função através da qual lhe dê condição para melhorar (WERLANG, 2013).

\section{O Papel do brincar na Psicanálise}

De acordo com Vargas et al.(2016), qualquer método psicanalítico aplicado visa promover a possibilidade do paciente se aproximar, na medida em que suas defesas psíquicas o permitem, de apropriações dolorosas que se reluta saber e aceitar: sejam sobre a doença ou sobre si próprio.

Para Anna Freud, o brinquedo e o brincar eram os melhores representantes dos processos interiores da criança, trazendo neles todo o significado e sentido dos atos da criança. Assim, para a autora, seria a ferramenta mais apropriada para análise com crianças (ARENALES-LOLI et al., 2013).

De acordo com Kishimoto (1998) apud Guilhermino (2005), há uma diferenciação entre o jogar e o brincar. Segundo ele, o brincar não apresenta um sistema de regras para sua utilização, ao contrário dos jogos. Entretanto, Guilhermino (2005) em seu trabalho considera os conceitos de Piaget (1975), que apontam que essas duas atividades lúdicas não se diferem, pois apresentam regras, seja de forma explícita, como o xadrez, seja de forma implícita, como brincar de casinha.

Para Costa (2013), o brincar da criança é diferente de qualquer outra atividade por toda ação e imaginação envolvida no processo. Já o brinquedo não é uma ação simbólica no sentido próprio do termo, de forma que é preciso motivá-la. Se o brinquedo envolve a realização dos desejos, então podemos considerar que o brinquedo e toda situação imaginária envolvida na brincadeira, ganha uma atmosfera emocional. Isso permite à criança aprender e se adequar a regras, pois não existe brinquedo sem regras.

De acordo com Affonso (2012, p. 15):

Na criança pequena o mecanismo de repressão é menos
rígido, facilitando o acesso aos conteúdos inconscientes.
Porém, era necessário dispor de recursos para alcançar esse
universo que estava mais além da palavra. A psicoterapia
psicanalítica do adulto é feita principalmente pelos relatos
verbais dos pacientes, mas, como a verbalização da criança
pequena é geralmente escassa, foi necessária uma inovação
técnica para favorecer uma comunicação mais significativa.

Para Affonso (2012), brincar é coisa séria, conforme a frase da psicopedagoga Dra. Sandra Kraft do Nascimento daAssociação Brasileira de Brinquedotecas: "Obrincar é tão importante para a criança como trabalhar é para o adulto.” O autor afirma que pelo brincar, a criança pode ser tornar ativa, criativa e tem a oportunidade de se relacionar com os outros,também a faz feliz e, por isso, mais propensa a ser bondosa, a amar o próximo, a ser solidária. Para a criança alcançar o pensamento abstrato do adulto, ela precisa percorrer todas as etapas de seu desenvolvimento físico, cognitivo, social e emocional. Seu primeiro apoio nesse desenvolvimento é a família. Posteriormente, esse grupo se amplia com os colegas de brincadeiras e a escola.

$\mathrm{O}$ brincar representa um vínculo direto e imediato 
com a criança, sendo naturalmente associado a ela desde o início de sua vida. De maneira geral, acreditase que durante toda a história da humanidade a criança teve brinquedo e brincou. Uma vez que não tem ainda a linguagem desenvolvida, a criança transmite seu mundo interno e influências familiares pelo brincar (AFFONSO; TEIXEIRA, 2015).

Em concordância, Silva et al. (2017) apontam que é da natureza humana brincar e que sua função primordial é a descoberta do mundo, possibilitando que sejam desenvolvidas diversas capacidades, como atenção, memória, imitação, habilidades motoras e agilidade. Além disso, é um facilitador do processo de socialização, comunicação e expressão, e a principal forma com que a criança exercita sua criatividade e fantasia.

A brincadeira é a vida da criança, pois permite que ela desenvolva os seus sentidos, adquira habilidades, reconheça objetos, suas características, textura, forma, tamanho, cor e som. O brincar alegra e motiva as crianças, conduzindo a relacionamentos grupais (DIEGUES et al., 2018).

Para Almeida (2017), o brincar traz em si a possibilidade de serem representados os medos, angústias e representações parentais (ou substitutos), constituintes do espaço interno do sujeito que brinca. Ao se projetar numa história viva de si mesmo, a criança reconta suas histórias em que ela é a própria autora no seu palco interno, constituindo enredos projetivos.

Adicionalmente, Winnicott (1975 apud DIEGUES et al., 2018) afirma que o brincar possibilita que as crianças entrem em contato com o mundo e com a cultura, e que através desses elementos, revelem sua maneira de ser, de estar no mundo e de expressar-se. Dessa forma, o ambiente do brincar atua como um mediador entre as necessidades e desejos da criança, e os limites e possibilidades da realidade externa, permitindo que ela adquira novas experiências.

Desse modo, ainda segundoWinnicott (1975), o ambiente que vai sendo descoberto pela criança, é destruído, criado e reinventado, oferecendo a oportunidade de uma ilusão criativa, agente de descobrimento, mesmo sabendo-se que o mundo já estava lá para ser criado. O brincar é sempre uma experiência criativa que tem começo, meio e fim.

Conforme Pedroso, Lobato e Magalhães (2016), a identificação consciente e inconsciente da criança com um brinquedo ou brincadeira em específico contribui para a escolha que ela realizará frente a uma variedade de opções nas quais o brincar será exercido.

Por tudo isso, o brincar pode ser uma forma de comunicação para a psicanálise, que foi desenvolvida a partir de uma forma altamente especializada de brincar, como forma de comunicação consigo mesmo e com os outros. Cada autor traz uma contribuição diferente do que venha a ser o brincar, entretanto estão de comum acordo em relação a sua importância, tanto pelo símbolo que ele traz, tanto pelo ato de brincar (PAULA; MARASCA; SHMIDT, 2017).

Capelli e Oliveira (2015) destacam que a técnica criada por Melanie Klein consiste na utilização de jogos, e a partir do brincar a criança tem a oportunidade de demonstrar os seus desejos, suas fantasias e experiências de um modo simbólico. Para adquirir um entendimento, deve-se decifrar cada símbolo e o seu significado, destacando a relação de cada elemento com o todo. Para as crianças a associação livre está relacionada ao ato de brincar, sendo este seu modo natural de se expressar e nomear os objetos internos em relação ao mundo externo.

Os mesmos princípios são aplicados na ludoterapia é derivada da expressão inglesa play-therapy, podendo ser literalmente traduzida como "terapia pelo brincar". Este brincar tem por objetivo promover ou restabelecer o bem-estar psicológico da criança por meio de atividades lúdicas. Tem sido muito utilizada para o tratamento de crianças com distúrbios emocionais, neuróticos ou psicóticos (FONSECA, 2014; THERENSE, 2019).

Conforme Nasio (1995) e Gomes e Franca (2012), a técnica psicanalítica do brincar desenvolvida por Melanie Klein não se reduz à ludoterapia (PlayTherapy), cujo princípio consiste em oferecer ao paciente uma possível descarga emocional pela qual ele se libere de um afeto desagradável, por estar ligado à lembrança de um acontecimento traumático que ele repetiria inconscientemente.

De acordo com Paula, Marasca e Shmidt (2017), Arminda Aberastury foi a responsável por introduzir a caixa de brinquedos no setting terapêutico, pois seria capaz de viabilizar a projeção das fantasias e facilitar a elaboração traumática. A caixa tem representações inconscientes, simbolizando o mundo interno da criança, aquilo que ela não expressa verbalmente através de um discurso organizado. Assim, torna possível a compreensão do sujeito.

Para Rocco e Santos (2016), o processo avaliativo realizado com crianças é uma prática valiosa, porém complexa, uma vez que a criança possui funcionamento psíquico diferente do adulto, de forma que a sua sessão deve ser vista como um "convite ao sonho". É por meio do brincar e de uma atmosfera de não exigência que o analista pode realizar interpretações, uma vez que a criança expressa seus desejos, fantasias e experiências de forma simbólica. Quando se fala de brincar, no campo analítico, compreendemos o valor projetivo de um recurso que é capaz de esclarecer e demonstrar aspectos da personalidade infantil. Por isso, o objetivo não é brincar com a criança, mas possibilitar a expressão por meio da representação lúdica.

Nesse sentido, é importante valorizar o que acontece nos espaços intermediários entre paciente e terapeuta, pois é no inesperado, no encoberto e no 
transicional que se instaura a situação analítica e as possibilidades de um novo começo (ROCCO: SANTOS, 2016).

Para que haja interpretação, o analista deve levar em conta diversos parâmetros, que Melanie Klein expõe de maneira rigorosa. É preciso guardar os detalhes mais ínfimos do brincar; assim, os encadeamentos aparecerão e a interpretação será efetiva. É necessário levar em conta o material que as crianças fornecem durante a sessão: brinquedo, dramatização, água, recorte ou desenho; a maneira como brincam; a razão por que passam de uma brincadeira para outra; e os meios que escolhem para suas representações (NASIO, 1995).

De acordo com Klein (1926 apudNASIO, 1995, p. 143):

Todo esse conjunto de fatores, que muitas vezes parece confuso e desprovido de significação, afigurase-nos lógico e repleto de sentido, e suas fontes e os pensamentos que the são subjacentes revelam-se a nós, quando o interpretamos exatamente como um sonho.

De acordo com Fulgêncio (2008) para Klein a interpretação através do brincar ainda tinha o poder de modificar a ansiedade infantil associada à fantasia inconsciente. A interpretação, reveladora da fantasia inconsciente, tinha o poder de fazer com que a criança diminuísse, o seu grau de fixação a essa fantasia inconsciente e aos objetos e pessoas a ela associada.

Em concordância, Belo e Scodeler (2013), através da capacidade de brincar, o indivíduo consegue, a cada novo contato com a experiência, lançar sobre ela um novo olhar, tendo a possibilidade de encontrar saídas criativas para velhos problemas. Assim, nesse ponto o psicanalista pode trabalhar para que o brincar seja possível e não apenas com uma técnica para análise, mas também como um meio terapêutico si mesmo por preservar no indivíduo aquilo que lhe é genuinamente seu.

\section{Ludodiagnótico}

Segundo Affonso, Guedes e Araújo (2016) o ludodiagnóstico é uma ferramenta utilizada pelo psicólogo com a criança, após as entrevistas iniciais com os pais, e tem como objetivo o diagnóstico e intervenção clínica, através de materiais lúdicos que possibilitam a expressão de conteúdo do mundo interno e externo do paciente.

Logo, o ludodiagnósticoé um instrumento utilizado que permite ao terapeuta a investigação e o diagnóstico do funcionamento mental da criança.É utilizado pelo profissional de psicologia para estabelecer um vínculo terapêutico com a criança, em que esta, por meio de brinquedos, estruturados ou não, exterioriza a sua personalidade (FERNANDES, 2016).
Conforme Affonso (2012), o ludodiagnóstico é uma técnica projetiva, geralmente utilizada em situações de psicodiagnóstico infantil como uma das etapas de um dos conjuntos de técnicas e testes utilizados para o diagnóstico clínico.O termo "projetiva", indica que essa técnica busca analisar o paciente através da projeção que, segundo Lopes (2018), se caracteriza como uma defesa primária do psiquismo humano comum a todas as estruturas psíquicas a qual o sujeito projeta em um objeto ou a outro sujeito desejos que provêm do seu inconsciente e que suas origens são desconhecidas ou negadas de sua consciência, atribuindo elementos próprios a uma alteridade que lhe é externa.

Rocco e Santos (2016) afirma que se trata de um recurso singular para alcançar o universo infantil, em que, através de brinquedos, estruturados ou não, o vínculo terapêutico se estabelece e propicia a auto expressão e projeção da criança.

De acordo com Weiss (2012 apud FERREIRA,2018), a utilização do termo lúdico, tanto para diagnóstico quanto no tratamento, se refere ao processo de jogar, brincar, representar e dramatizar como condutas semelhantes na vida infantil. Conforme já visto, a técnica do jogo na psicanálise foi elaborada por Melanie Klein, Anna Freud, dentre outros estudiosos, aprofundando o simbolismo inconsciente.

Para Santos e Werba (2016) a atitude lúdica diz respeito a uma posição mental considerada livre por excelência, tendo por paradigma o brincar da criança que frui em liberdade o prazer de se entregar a seus objetos de relacionamento, entretenimento e divertimento.

De acordo com Ramos (2014), existem várias designações atribuídas ao conceito de ludodiagnóstico, tais como: hora do jogo, observação lúdica, hora lúdica, entrevista inicial ou entrevista clínica com a criança. Isso ocorre devido à variedade de posturas profissionais, de materiais usados, técnicas subjacentes, tipos de abordagens, mas todas elas têm como base o trabalho com a criança ou adulto no contexto clínico psicológico.

Essa técnica tem a finalidade de trazer à consciência as emoções censuráveis, originando uma descarga afetiva, em queé permitido à criança manifestar a sua raiva e o ódio através da criação de personagens ou representações lúdicas. Este método de observação direta permite ao psicólogo a aquisição de informações relevantes que a criança, de outra forma, não consegue exprimir (FERNANDES, 2016).

Por ser uma técnica livre, a criança pode escolher a sua forma de expressão, dramatizando, conversando verbalmente ou desenhando. Cabe ao psicólogo interpretar esses fatores, mediante observação e associação livre, estabelecendo uma comunicação e um vínculo terapêutico com a criança inserida no contexto psicanalítico (AFFONSO; GUEDES; ARAUJO, 2016).

Conforme destacado por Affonso e Teixeira 
(2015), é importante observar que se configura como um instrumento que requer treino e habilidade para sua aplicação, pois, embora a técnica consista na utilização da brincadeira infantil, o objetivo não é brincar com a criança, e sim permitir que ela expresse através dos brinquedos as dificuldades que porventura esteja enfrentando, requerendo habilidade do profissional.

Semelhantemente, Ramos (2014) afirma que o ludodiagnóstico é um instrumento de investigação clínica que utiliza o lúdico para estabelecer um vínculo terapêutico com o paciente visando o diagnóstico da sua personalidade. Para que isso ocorra, é necessário que o terapeuta infantil apresente um amplo repertório lúdico que the permita favorecer a ligação terapêutica. $\mathrm{O}$ ludodiagnóstico se baseia em momentos de observação, investigação, levantamento de hipóteses e pesquisa, principalmente no âmbito do desenvolvimento do psiquismo infantil, pretendendo a intervenção, o mais precocemente possível, num processo dinâmico e flexível.

Para Affonso (2011), o ludodiagnóstico aplica o conceito psicanalítico de projeção, que consiste na operação pela qual o indivíduo expulsa de si e localiza no outro, pessoa ou coisa, qualidades, sentimentos e desejos que desdenha ou recusa em si. Assim, é utilizada em diagnósticos para obtenção de informações indiretas, às quais o sujeito não tem acesso ou não consegue expressar, através de estímulos para a obtenção de dados, proporcionando a oportunidade de autoexpressão sem a necessidade do depoimento verbal direto. No entanto, também utiliza alguns questionamentos. $\mathrm{O}$ psicoterapeuta faz perguntas muito semelhantes ao que comumente é utilizado nos testes projetivos, tais como: "Quem poderia ser aquele boneco?", “Com quem poderia morar?", "O que ele está fazendo?", "O que irá fazer depois?", exigindo por parte do aplicador um treino específico.

Lopes (2018) aponta que não basta que o profissional facilite e proporcione um ambiente para o brincar, mas é necessário que o mesmo assuma uma postura de conhecimento técnico sobre esse procedimento, que desvendeconteúdos valiosos para compreensão dos sintomas e conflitos internos, aosquais, com base nas análises desse brincar, o profissional, com clareza de seus pressupostos,proporcioneuma intervenção pontual e eficaz.

De acordo com Real e Marques (2017), para realizar o ludodiagnóstico em crianças é necessário bastante conhecimento a respeito do significado do brinquedo para a criança, contando com subsídios teóricos para a interpretação das brincadeiras realizadas, levando-se em conta uma premissa básica da psicanálise, segundo a qual através do brinquedo a criança pode elaborar o que sofre passivamente.

De acordo com Ribeiro (2013), para que o ludodiagnóstico seja feito da maneira adequada, é importante que sejam fornecidas ao terapeuta todas as informações necessárias que incluem dados do desenvolvimento da criança, da sua relação com os pais e com os outros, desempenho escolar ao nível de resultados acadêmicos e ao nível comportamental e de interação social, entre outros. Estes dados vão ajudar a uma compreensão, ainda que parcial, de como lidar com a situação.

A escolha do brinquedo relaciona-se à necessidade de usar um instrumento que possibilite a expressão de emoções e afetos. Contribuirá para a elaboração da fantasia e da realidade da criança e de sua angústia referente à sua própria vivência. $\mathrm{O}$ brincar, portanto, está relacionado aos aspectos inconscientes da criança e compete ao clínico investigar a sua expressão (PEREIRA; SOUZA; SHMIDT, 2017).

Para realização desse processo, Fernandes (2016) e Leonardi (2015) indicam que os materiais utilizados devem ser de estatura pequena, o que possibilita à criança a sua fácil manipulação, conseguindo o controle sobre os brinquedos, sem pôr em risco a vida da criança, sendo que os mesmos devem ser representativos e reconhecíveis à sua realidade e respeitar a sua cultura. A caixa de ludo deve incluir elementos que analisem e enfatizem o processo de desenvolvimento, uma vez que o brincar de forma representativa faz parte de uma das etapas do modo de socialização da criança.Em geral, são usados materiais estruturados, tais como: família de bonecos,casinha com quarto, banheiro, sala e cozinha, animais domésticos e selvagens, etc., e materiais não estruturados, como: lápis, massa de modelar, brinquedos de construção.

Analisando esses brinquedos e a forma de brincar da criança nas sessões ludoterápicas, podemos observar as representações das vivências infantis e que podem envolver: o ambiente, a dinâmica familiar, o contexto geral em que a criança está inserida, seu papel e a sua função da família e, também, possíveis dificuldades, como por exemplo, as escolares (AFFONSO; GUEDES; ARAUJO, 2016).

Affonso (2012) descrevem alguns procedimentos técnicos para aplicar o ludodiagnóstico na psicanálise infantil:

a) os brinquedos devem ser de um determinado tamanho, formato e variedade;

b) a cada sessão, os brinquedos devem ser guardados pela criança acompanhada pelo terapeuta em uma caixa de madeira (específica para cada criança) trancada com cadeado em um armário, verificando a guarda, sempre no mesmo lugar;

c) a sala deve ter chão e paredes laváveis, móveis simples, uma torneira e uma pia;

d) a sessão começava e terminava sempre no horário combinado, de forma que se o paciente se atrasasse, perderia o tempo de atraso;

e) durante a sessão a porta da sala de fica trancada, 
como na sessão de adultos;

f) o contato com os pais é reduzido ao mínimo necessário.

Ainda segundo os autores, existem motivos que levam àaplicação desses procedimentos. Os brinquedos devem ser pequenos para caber na caixa e não devem ser complicados para que sejam facilmente manipuláveis, de forma a facilitar a expressão na brincadeira. A variedade de brinquedos é restrita para ocupar menos espaço e ser acessível à capacidade de imaginação da criança.

Guardar os brinquedos numa caixa com cadeado fornece a segurança de que eles permanecerão do mesmo modo que foram deixados na sessão anterior e que ninguém abrirá a caixa. $\mathrm{O}$ fato de a criança acompanhar e conferir a caixa mostra à criança que seu material é inviolável e tem a garantia da guarda do terapeuta, dando a ela a segurança de que somente ela e o terapeuta têm acesso à mesma (AFFONSO, 2012).

Conforme Diegues (2015), a proposta de avaliação do brincar mais utilizada, como referencial teórico-técnico dentro da abordagem psicanalítica no ensino da técnica ludodiagnóstica foi obtida através da elaboração de um guia de pautas que oferecem critérios sistematizados e coerentes para orientar a análise. Os indicadores propostos são: escolha de brinquedos, modalidade de brinquedo, psicomotricidade, personificação, criatividade, capacidade simbólica, tolerância à frustração e adequação à realidade. Assim, são esperados os seguintes parâmetros:

a) Para uma criança de três anos: brincar egocêntrico, com perguntas sobre os objetos, mas sem envolver o entrevistador como participante ativo da brincadeira. Atividade espontânea e lábil, o que faz com que caminhe de uma brincadeira para a outra sem terminar nenhuma. A atenção está centrada no objeto.

b) Para uma criança de quatro a sete anos: maior aproximação do real, com crescente preocupação pela veracidade da imitação exata. Pode incluir intencionalidade, o propósito explícito de realizar determinada tarefa.

c) Para uma criança de sete a onze anos: esboços de regras estabelecidos. Pode atribuir e assumir papéis próximos à realidade. Tem noção da brincadeira mútua e consciência da alteração de regras.

No ponto de vista de MaudMannoni, o material lúdico deve ser logo introduzido na entrevista diagnóstica com os pais, de modo a observar o brincar da criança que acompanha o diálogo dos pais com o terapeuta. O conhecimento das relações familiares e sociais do paciente constitui um fator importante na elaboração do diagnóstico (RAMOS, 2014).

Para Ferreira (2018) e Gamba (2015), nesse processo dinâmico de investigação, há a apropriação do objeto, vinculando motivação lúdica ao desenvolvimento do pensamento simbólico nos processos imaginários. Logo, o brincar cria uma situação imaginária e um comportamento regrado - momentos oportunos para a observação psicopedagógica e o consequente levantamento de hipóteses para o caso clínico.

Affonso (2012) destaca que, apesar da nomeada importância da observação no ludodiagnóstico, ela não é o único e exclusivo instrumento de investigação diagnóstica, possuindo, inclusive, alguns limites como técnica de investigação clínica. Com outras técnicas de investigação, tais como o desenho e os testes projetivos, o profissional pode, sem a consideração das noções de espaço, tempo e causalidade, "direcionar" o seu raciocínio e conduta clínica.

\section{Considerações finais}

Considerando as dificuldades encontradas na análise de crianças, pela limitação da fala, muitos autores encontraram no brincar uma saída para tal. Por meio dessa atividade, que é própria da natureza da criança, é possível identificar sentimentos e dificuldades enfrentadas pelas mesmas. Dessa forma, o brincar pode representar uma técnica de diagnóstico projetiva, na qual o paciente expõe em um objeto aquilo que sente.

Isso é possível porque o brincar é uma atividade natural da criança, com diversas funções que vão sendo reveladas ao longo do seu desenvolvimento. Por exemplo, auxilia no desenvolvimento motor e é capaz de expressar os sentimentos interiorizados que são enfrentados ao longo do seu processo de independência, além de outras situações que possam estar ocorrendo com a mesma. Além disso, torna possível a integração da criança dentro de ambientes sociais com interação em grupo com outras crianças.

Assim, a forma como a criança se relaciona com o brinquedo, com jogos, e posteriormente com outras crianças (seus pares), revela muito dos seus sentimentos e a forma como a mesma está tentando lidar com o que lhe ocorre. Esse brincar pode ser utilizado tanto como instrumento diagnóstico, para identificar os pontos que precisam ser tratados no paciente, quanto como um método para terapia, promovendo ou restabelecendo o bem-estar psicológico da criança.

O ludodiagnóstico se caracteriza como essa técnica que busca através de observações do brincar, estudar o comportamento da criança e as emoções que estão sendo retratadas em suas ações. É uma forma inicial aplicada para conhecer o paciente e determinar as áreas que precisam ser tratadas.

Ainda que tenha diferentesatribuições, trata-se do mesmo princípio, que é a partir das atividades naturais para a criança, contidas no brincar, que ela possa dramatizar, trazendo para o exterior suas angústias. Dessa forma, há a oportunidade de autoexpressão sem a utilização de linguagem verbal, facilitando o processo de diagnóstico desse público específico. 
Destarte, ficaram evidenciadasa validade e a importância dessa técnica, como instrumento diferenciador no tratamento de crianças de diversas idades. Os diversos autores envolvidos na criação da mesma contribuíram grandemente para o processo de diagnóstico e tratamento infantil.

Entretanto, para que seja realizado de forma adequada, o ludodiagnóstico deve ser entendido com clareza pelos profissionais, pois não deve ser encarado como uma brincadeira, mas como um método, com procedimentos a serem seguidos. Dessa forma, será possível estabelecer vínculos com a criança e representar, além de uma técnica inicial, uma técnica terapêutica.

\section{Referências}

AFFONSO, Rosa Maria Lopes (Org.). Ludodiagnóstico: investigação Clínica Através do Brinquedo. Porto Alegre: Artmed, 2012. 288 p.,25 cm. ISBN 978-85-363-2695-5.

AFFONSO, Rosa Maria Lopes. A contribuição da análise das noções de espaço, tempo e causalidade nas técnicas projetivas diagnósticas: ludodiagnóstico e desenho da figura humana. Psicologia: teoria e prática, São Paulo, v. 1, n. 13, p.101-116, set. 2011. Disponível em: <http://pepsic. bvsalud.org/pdf/ptp/v13n1/v13n1a08.pdf>. Acesso em: 25 de fev. 2019.

AFFONSO, Rosa Maria Lopes; GUEDES, Fernanda Ferreira; ARAUJO, Simone Canola. Ludodiagnóstico: a Dependência Química e a Dinâmica Familiar. Psicologia.pt, São Paulo, v. 13, n. 1, p.1-16, nov. 2016. Versão Online. ISSN 1646-6977. Disponível em: <http://www.psicologia.pt/artigos/ textos/A1033.pdf>. Acesso em: 25 mar. 2019.

AFFONSO, Rosa Maria Lopes; TEIXEIRA, Thais. A Ludoterapia como Forma de Intervenção em Lutos Infantis. Facisa Online, [S. 1.], v. 4, n. 1, p.12-28, jul. 2015. ISSN: 2238-8524. Disponível em: <http://periodicos. faculdadecathedral edu.br/revistafacisa/article/view/78/66>. Acesso em: 08 mar. 2019.

ALMEIDA, João Serra de. Somos Contadores de Histórias: brincadeira lúdica e criativa de recolher e (re)escrever (estórias) histórias para crianças. Psicologia da Criança e do Adolescente, [S.1.], v. 8, n. 2, p.169-180, ago. 2017. Disponível em: <https://www.researchgate.net/ publication/333668484_Somos_contadores_de_hiStorias_Brincadeira ludica e criativa de recolher e reescrever estorias historias para a crianca We are accountants of histories ludic and criative game to collect_and_reverse_>. Acesso em: 06 jan. 2019

ARENALES-LOLI, Maria Salete. et al. O Jogo como mediador na entrevista: um novo lugar no processo psicoterápico com adolescentes. Academia Paulista de Psicologia, São Paulo, v. 33, n. 85, p.405-426, dez. 2013. Disponível em: <http://pepsic.bvsalud.org/pdf/bapp/v33n85/a13.pdf>. Acesso em: 06 jan. 2019.

ARENALES-LOLI, Maria Salete. O atendimento psicoterápico com adolescentes: inovações técnicas com o uso do mediador clínico - jogo Túnel do tempo. 2014. 178 f. Tese (doutorado) - Universidade Estadual Paulista Júlio de Mesquita Filho, Faculdade de Ciências e Letras de Assis, 2014. Disponível em: <http://hdl.handle.net/11449/114010>. Acesso em: 13 de fev. 2019.

BELO, Fábio; SCODELER, Kátia. A importância do brincar em Winnicott e Schiller. Tempo Psicanalitico, Rio de Janeiro, v. 45, n. 1, p.91-109, jun. 2013. Disponível em: <http://pepsic.bvsalud.org/pdf/tpsi/v45n1/v45n1a07. pdf>. Acesso em: 01 fev. 2019.

CAPPELLI, TielenFranciosi; OLIVEIRA, Luiz Ronaldo Freitas de. Psicoterapia psicanalítica de uma criança que está sob a guarda da avó: estudo de caso. Aletheia, Canoas, v. 48, n. 47, p.91-105, dez. 2015. Disponível em: $<$ http://pepsic.bvsalud.org/pdf/aletheia/n47-48/n47-48a08.pdf $>$. Acesso em: 23 nov. 2018 .

CARNEIRO, Vanessa Miranda Santos de Paula; SILVA, Marcelo Pinheiro da. Quando brincar é viver criativamente: o encontro da abordagem gestáltica com a winnicottiana. IGT na Rede, Rio de Janeiro, v. 10, n. 19, p.335-350, out. 2013. ISSN: 1807-2526. Disponível em: <https://www.igt.psc.br/ojs/ viewarticle.php?id=437>. Acesso em: 10 fev. 2019.

COSTA, Beatriz Cruz da.Mediadores Dialógicos na Terapia Infantil: o Uso de Desenhos, Histórias e Brincadeiras. 2013. Disponível em: <http:// www.puc-rio.br/pibic/relatorio_resumo2013/relatorios_pdf/ctch/PSI/PSIBeatriz\%20Cruz\%20da\%20Costa.pdf $>$. Acesso em: 15 dez. 2018.

COSTA, Terezinha (Org.). Psicanálise com Crianças. 3. ed. Rio de Janeiro: Zahar, 2010. 88 p. (Passo a Passo). Vol. 75. Inclui bibliografia. ISBN 97885-7110-994-0.

DIEGUES, Débora. O modelo lúdico na análise do brincar de crianças com Síndrome de Down. 2015. 88 f. Dissertação (Mestrado em Psicologia) - Universidade Presbiteriana Mackenzie, São Paulo, 2015. Disponível em: $<$ http://tede.mackenzie.br/jspui/handle/tede/1651>. Acesso em: $10 \mathrm{de}$ abr. 2019

DIEGUES, Débora et al. O Modelo Lúdico em crianças com Síndrome de Down. Psicologia Revista, [S.1.], v. 27, n. 1, p.151-171, 26 jul. 2018. Portal de Revistas PUC SP. http://dx.doi.org/10.23925/2594-3871.2018v27i1p151 170. Disponível em: <https://revistas.pucsp.br/psicorevista/article/ view/33608/26215>. Acesso em: 11 jan. 2019.

FELICE, Eliana Marcello de. O lugar do brincar na psicanálise de crianças. Psicologia: teoria e prática, São Paulo, v. 5, n. 1, p.71-79, jun. 2003 Disponível em: <http://pepsic.bvsalud.org/pdf/ptp/v5n1/v5n1a06.pdf $>$. Acesso em 01 de jun. de 2018 .

FERNANDES, Sandra Isabel David.Psicologia Clínica em Contexto Escolar. 105 f. Dissertação (Mestrado) - Curso de Psicologia Clínica, Universidade Lusíada de Lisboa, Lisboa, 2016. Disponível em: <http:/ repositorio.ulusiada.pt/bitstream/11067/2654/1/mpc_sandra_fernandes dissertacao.pdf>. Acesso em: 05 de nov. 2018.

FERREIRA, Danielle de Almeida Galante. Na Contramão da Medicalização na Educação: desnaturalizar e despatologizar o fracasso escolar. Aleph, Niterói, v. 1, n. 31, p.339-362, dez. 2018. ISSN 1807-6211. Disponível em: $\quad<$ http://www.revistaleph.uff.br/index.php/REVISTALEPH/article/ view/814/479>. Acesso em: 25 abr. 2019.

FONSECA, Marileise Roberta Antoneli. Compreendendo o brincar da criança com câncer por meio do brinquedo terapêutico dramático. 2014. 118 p. Dissertação (mestrado) - Universidade Estadual de Campinas, Faculdade de Enfermagem, Campinas, SP. Disponível em: $<$ http://www. repositorio.unicamp.br/handle/REPOSIP/283872>. Acesso em: 25 ago. 2018 .

FREITAS, Maiara Castro de. Psicoterapia de crianças: o brincar como método de tratamento psicanalítico. Multiciência Online, Santiago, Uruguai, v. 5, n. 1, p.114-133, abr. 2016. ISSN 2448-4148. Disponível em: <http:/ urisantiago.br/multicienciaonline/adm/upload/v2/n3/4158e04e9962931ffb5 80c9572b84a13.pdf>. Acesso em: 10 abr. 2019.

FULGENCIO, Leopoldo. O brincar como modelo do método de tratamento psicanalítico. Revista Brasileira de Psicanálise, São Paulo, v. 42, n. 1 , p.124-136, mar. 2008. Disponível em: <http://pepsic.bvsalud.org/pdf/rbp/ v42n1/v42n1a13.pdf $>$. Acesso em: 04 out. 2018.

GAGLIOTTO, Giseli Monteiro et al. Violência Sexual contra Adolescente: um estudo de caso no Neddij de Francisco Beltrão. In: SEMINÁRIO NACIONAL DE EDUCAÇÃO, DIVERSIDADE SEXUAL E DIREITOS HUMANOS, 3., 2014, Vitória. Anais... . Vitória: GEP, 2014. p. 1-12.

GAMBA, Moara de Oliveira. Perícia Psicológica e Violência Sexual Infantil: conhecendo a atuação dos psicólogos no Maranhão. $136 \mathrm{f}$. Dissertação (Mestrado) - Curso de Psicologia, Universidade Federal do Maranhão, São Luís, 2015. Disponível em: <http://tedebc.ufma.br:8080/ jspui/handle/tede/1288>. Acesso em: 30 set. 2018

GOMES, Nívea de Fátima; FRANÇA, Cassandra Pereira. Ainda interpretamos crianças à maneira de Melanie Klein? Estilos da Clinica, São Paulo, v. 17, n. 2, p.290-305, dez. 2012. Disponível em: <http://pepsic. bvsalud.org/pdf/estic/v17n2/v17n2a08.pdf>. Acesso em: $30 \mathrm{dez} .2018$

GUILHERMINO, Luciane da Silva. O Lúdico no Diagnóstico Psicopedagógico. 2005. 59 f. Monografia (Especialização) - Curso de Psicopedagogia, Universidade Candido Mendes, Rio de Janeiro, 2005. Disponível em: $<$ http://www.avm.edu.br/monopdf/6/LUCIANE\%20DA\%20 SILVA\%20GUILHERMINO.pdf>. Acesso em: 30 mar. 2019.

KLIPAN, Marcos Leandro; MELLO NETO, Gustavo Adolfo Ramos. A neurose obsessiva sob a ótica de Melanie Klein. Ágora: Estudos em Teoria Psicanalítica, [S.1.], v. 15, n. 2, p.311-325, dez. 2012. FapUNIFESP(SciELO). http://dx.doi.org/10.1590/s1516-14982012000200008. 
LEONARDI, Liliana Cremaschi. Caixa Lúdica para Idosos: uma nova proposta psicoterapêutica. 2015. 138 f. Tese (Doutorado) - Curso de Psicologia Clínica, Instituto de Psicologia, Universidade de São Paulo, São Paulo, 2015. Disponível em: <http://www.teses.usp.br/teses/disponiveis/47/47133/tde16022016-122611/pt-br.php>. Acesso em: 29 abr. 2019.

LOPES, Rosimeri Bruno. Uma Revisão Sobre a Psicanálise Infantil. Psicologado, 2012. Disponível em: $<$ https://psicologado.com.br/abordagens/ psicanalise/uma-revisao-sobre-a-psicanalise-infantil>. Acesso em:7Jul 2018.

LOPES, Yan de Jesus. O ludodiagnóstico e as técnicas projetivas como instrumento psicoterapêutico. Psicologia.pt, São Paulo, v. 3, n. 5, p.1-8, set. 2018. Disponível em: <http://www.psicologia.pt/artigos/textos/A1242.pdf>. Acesso em: 23 mar. 2019.

NASIO, Juan-david. Introdução às obras de Freud, Ferenczi, Groddeck, Klein, Winnicott, Dolto, Lacan. Rio de Janeiro: Zahar, 1995. 307 p. Tradução de Vera Ribeiro. Bibliografia. ISBN 978-85-7110-325-9.

PAULA, Letícia de.Psicanálise Infantil: uma Interseção entre a Teoria e a Prática. 2017. 40 f. Monografia (Especialização) - Curso de Psicologia Hospitalar, Fundação do Desenvolvimento Administrativo, São Paulo, 2017

PAULA, Tainá Regina de; MARASCA, Mariucha Roberta; SHMIDT, Lorena Miranda. Análise da Família na Tendência Antissocial: um Estudo de Caso na Visão da Psicanálise da Criança. In: COLOQUIO ESTADUAL DE PESQUISA MULTIDISCIPLINAR, 2., 2017, Mineiros. Anais... . Mineiros: Unifirmes, 2017. p. 1 - 15

PEDROSO, Janari da Silva; LOBATO, Caroline Pinheiro; MAGALHÃES, Celina Maria Colino. Brincar e Realidade: verbalizações de crianças em situação de acolhimento institucional. Psicologia em estudo, [S.1.], v. 21, n. 4, p.711-722, 6 jan. 2017. Universidade Estadual de Maringá. http://dx.doi. org/10.4025/psicolestud.v21i4.31806.

PEREIRA, Débora Souza; SOUZA, Pâmela Moreira; SHMIDT, Lorena Miranda. Caso LG: psicodiagnóstico nos comportamentos de transtorno de oposição, uma tendência antissocial. In: COLÓQUIO ESTADUAL DE PESQUISA MULTIDISCIPLINAR, 2., 2017, Mineiros. Anais... . Mineiros: Unifirmes, 2017. p. 1-12. Disponível em: <http://publicacoes.unifimes.edu. br/index.php/coloquio/article/view/333>. Acesso em: 05 abr. 2019.

RAMOS, Rosa Maria Saraiva Pires.A percepção dos profissionais de Educação Especial face à Ludoterapia em contexto educativo. 2014. 167 f. Dissertação (Mestrado) - Curso de Ciências da Educação na Especialidade em Educação Especial: Domínio Cognitivo-motor, Escola Superior de Educação João de Deus, Lisboa, 2014.

REAL, Luciane Magalhães Corte; MARQUES, Tania Beatriz Iwaszko(Org.). Psicopedagogia e TICs. Porto Alegre: Sead, 2017. 190 p. Disponível em: $<$ https://lume.ufrgs.br/handle/10183/150130>. Acesso em: 25 nov. 2018.

RIBEIRO, Célia Margarida da Silva. O Mutismo Seletivo e a Ludoterapia/ Atividade Lúdica: na perspetiva de profissionais ligados à educação. 2013. 99 f. Dissertação (Mestrado) - Curso de Ciências da Educação na Especialidade em Domínio Cognitivo-motor, Escola Superior de Educação João de Deus, Lisboa, 2013.

ROCCO, Thais Zamperline; SANTOS, Gilcineia Rose. Psicodiagnóstico infantil: uma visão além do brincar. Semina: Ciências Sociais e Humanas, [S.1.], v. 37, n. 1, p.93-103, 30 nov. 2016. Universidade Estadual de Londrina. http://dx.doi.org/10.5433/1679-0383.2016v37n1p93.

SAFRA, Gilberto. Uma Contribuição da Clínica do Self ao Estudo dos Testes Projetivos. 2012. Instituto de Psicologia da Universidade de São Paulo. Disponível em: <http://serefazer.psc.br/wp-content/uploads/2012/09/ contribuicao-self.pdf>. Acesso em: 26 nov. 2018

SANTOS, Bruna Caroline dos; WERBA, Graziela Cucchiarelli. Enurese Noturna como Sintoma de uma Criança Adotada. Conversa Interdisciplinares, Torres, v. 3, n. 5, p.1-17, nov. 2016. ISSN 1678-1740.

SEI, Maíra Bonafé; CINTRA, Maria Fernanda Vasques. Psicanálise de Crianças: histórico e reflexões atuais. Revista da Universidade Ibirapuera, São Paulo, v. 5, n. 1, p.1-8, jun. 2013.

SILVA, Mariana Luíza Becker da. O Caso do "Pequeno Hans": relação entre a fobia e sexualidade infantil. Psicologia.pt, São Paulo, v. 1, n. 12, p.1-8, nov. 2016. ISSN 1646-6977. Disponível em: <http://www.psicologia.pt/ artigos/textos/A1034.pdf>. Acesso em: 29 mar. 2019.
SILVA, Michelle Fernanda Arruda et al. O processo de psicoterapia infantil sob uma perspectiva psicanalítica. Revista Farol, Rolim de Moura, v. 4, n. 4, p.126-141, jun. 2017.

THERENSE, Munique. O processo ludoterapêutico na perspectiva fenomenológico-existencial das crianças em atendimento clínico. Revista da Abordagem Gestáltica, Goiânia, v. 25, n. 1, p.15-25, abr. 2019.

VARGAS, Vania Maria et al. Gamellito: desenvolvimento e avaliação em estudo piloto de um health game educativo e terapêutico para crianças com DM1. In: SBGAMES, 15., 2016, São Paulo. Proceedings... . São Paulo: Sbc, 2016. p. 1205 - 1209

WERLANG,Blanca Guevara.Entrevistalúdica.2013.Disponívelem: $<$ http:// professor.pucgoias.edu.br/SiteDocente/admin/arquivosUpload/17963/ material/Entrevista $\% 20 \mathrm{~L} \% \mathrm{C} 3 \%$ BAdica $\% 20-\% 20$ Texto.pdf $>$. Acesso em: 26 mar. 2019.

WINNICOTT, Donald Woods. O Brincar e a Realidade. Rio de Janeiro: Imago, 1975. 243 p. (Coleção Psicologia Psicanalítica). Tradução da primeira edição inglesa publicada em 1971. 